\title{
Business Letter
}
P. Cairo Mus.C.G 10281, $\mathrm{a}+\mathrm{b}+\mathrm{c}$
$11 \times 14.5 \mathrm{~cm}$
$3^{\text {rd }}$ Cent. BCE.

Provenance unknown.

Grenfel \& Hunt described this document in his catalogue: Three fragments of a letter from Diodoros to Heracleides, stating that he had been summoned by Artemidorus to bring samples of corn to the public granary in the 3rd century BCE.

Since the three pieces have been glued to modern paper for enforcement as it has been commonly used in many papyri of Grenfel and Hunt catalogue and it is almost impossible to rearrange the original pieces to get the original shape of this document; I used the Photoshop software to do that instead. Consequently, in order to distinguish the text of each fragment from the others, I have typed every text in a different color and restored them altogether in one text in a way by which as I assume it was originally written.

The text in general is incomplete. It contains 26 lines 13 complete and 13 incomplete lines.

This documetn is a letter written by $\Delta$ tó $\omega \rho o \zeta$ concerning an amount of wheat sent to

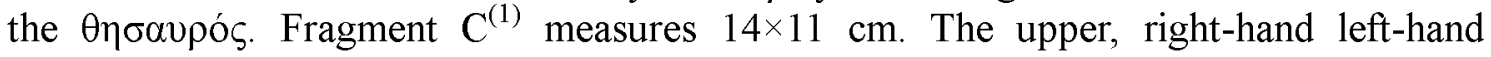
margins have been. The document has the upper and left margins. The upper margin is about $4.0 \mathrm{~cm}$., the left margin is ca. $2.7 \mathrm{~cm}$. The ligature of the letters at the right side reach to the very edge of the margin, other than at the second and fifth lines. The text is written on the recto. The hand is calligraphic, the letters are big, clear and illegible. The type of hand-writing indicates 3rd cent. BCE (cf. P. Gurob 1; 2. 3.).

Frag. B measures $8.9 \mathrm{~cm} \times 12.6 \mathrm{~cm}$, Frag. A measures $5.6 \mathrm{~cm} \times 8.6 \mathrm{~cm}$.

Only traces of the head of the letters of line 8 are preserved, consequently the letters and words are illegible. The end of document is lost.

Since there is no a close parallel to that document, as far as I know, these names of

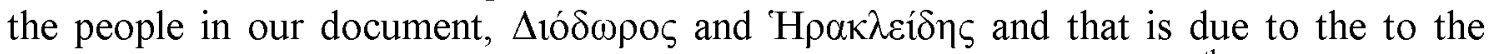
condition of the papyrus which is suffering from cutting off from its $8^{\text {th }}$ line, the status of those people could not be ascertained in spite of the fact that context of the document would indicate.

The alimentary grains which were collected \{reaped\} were left in the custody of the general stores in the villages. They had tasks like tasks of the banks individuals also were used to leave on it quantities of grains and the directors of these were receiving or transferring quantities of grains for slight rents on behalf of some individuals or paid on their names (C, Preaux, Politique de race ou politique de somethy, ch' d Eg XI 1939, p. 129).

Part of the king's grain's which were left on the stores were used up in the regions for paying part of the employees' salaries or for the army men, or giving the priests some aids in money and offering oblations and for defraying the expenses employees during being transported to carry out the official tasks and food for the army horses (2-Preaux, c. Les grecs en Egypte d'apres les archives de Zenon, Bruxelles. 1949. p. 30ff.)

(1) Fragment $\mathrm{C}$ has been formerly edit by me in my Ph.D Thesis in 1997 (unpublished), Ain Shams University, Department of Ancient European Civilization, faculty of Arts 


\section{Business Letter}

We should take into our consideration that the alimentary grains which were lent to them seeds for the next year. The most important tasks of bıkovónos was his supervision on transferring corn in the first occasion (Idem, p. 152).

This responsibility was distributed proportionally on the financial workers on the king's writers, on the directors of stores and the chief of the villages (P.Tebt 704 ii L7085)

The main subordination was falling on the task of the Areferenec to olkovouos, weinferred this comes a letter which the finance minister sent to olkovouos of the Arsinoite nome. In this letter, where the load was not sent in the right time, the expenses incused and you should pay the remainder and if you refused to do so you would be exposed to severe punishment. The grains were transferred to the stores from. The farmers and afterwards to the nearest river harbours on beasts. It seemed from several different documents that its use work was an obligatory duty (5- Preaux, C. (Les Grecs) op. Cit. p. 134).

But some of these basts and their drivers were used to work in the finance minister's letter was mentioned above. These services were done gratis, because the king's farmers and the sellers of the alimentary grains were bought on behlef of the king. They offered extra quantities from grains to defray the expenses of transport (6-P.Tebt 742-750.

The wages of donkey men's wages were being given in grains, but the government bought these from them at limited prices .. 7- Tebt 704 .

It seemed that king was using his right to impose his services on the people except in the emergency times. The king had great sheep and as to kings beats, there is no doubt, that they were used to convey the crops, but it seemed that they were not sufficient to this purpose and this lead to using the private beasts to perform that. When the grains were removed to the harbours, they were conveyed on the first ship (8- Tebt. III p. 67).

The king's ships were used for this purpose and the people's ships are equally so. It seemed that the donkey men and the sailors were arranged in companies or groups during the century B- C. (cf. P. Tebt 703 ii L 75-6).

The king encouraged the establishment such companies or ordered to be established. He was urged by his wish to assure the ways of transport and make them easy (10-BGU 1741-43). This document denoted that they were formed to guarantee that these loads of the king's grains would reach their submilling to without acting any fraudulently in them. These grins were measured with official measure ( $\mu \dot{\varepsilon} \tau \rho \circ \nu \delta 1 \kappa \alpha 10 v)$ which were brought especially from Alexandria and enclosed with the loads, (11-Preaux, C. op. cit. p. 146).

They contained some samples from the sent grains (P. Lille, 21, P.Hib 9.).

They could be sure that the loaded grains were not staken or exchanged on the way. The ships were anchored at night in certain places that might be police stations which were established on the river to ensure the river sailing during the disturbance. They used some units from the military fleet in the Nile to ensure the navigation. When the disturbance increased some armed guards were accompanying the ship (BGU. 1742-3).

These guards were chosen by the owners of estates. This meant that those who had 


\section{Business Letter}

some sources were considered guarantee to their financial responsibility (BGU 1742-3).

The grains which were sent convey to Alexandria were kept there in large stores. Part of these grains was distributed between those who were in the king's service. These were the employees, the soldiers, the king's men, the librarians and Mouseien soholas.

The other part was specified as food to the inhabitants of Alexandria therefore, this part was put for sale shown in the markets and the remainder of all the crops due was exported abroad (P.Tebt 103).

This third century document B-C proves that the crops were sent to the general store and the oıkovouos assigned to adjust the accounts of this store. It he found out any deficiently in the quantities of the oily grains, the responsibility nubordination of this fell on the toparcoj and contractor as well (Preaux, C. Op. cit. p. 147ff).

These two men were cooperating with each to gather the crops and send them to the general store. There was no doubt that the crops were sent to the general store to make the king to ensure enough supervision on the quantity of the crops. 17-P.Tebt 703. L12634.

I may refer to an instance published by Zaki Aly in this taxk (Essays and papers, A Miscellaneous Output of Greek Papyri From Greco-Roman Egypt, 1995, pp. 129-132) to testify that this system was applied in extensor in Roman Egypt. The local government in Egypt was principally concerned with the cultivation of grain, its collection and its transportation as well as its storage. Egypt was the chief grain supply of the Roman Empire, Rome depended upon the Egyptian grain especially wheat for at least four months every year. Grain was stored in public granaries for future transportation to Rome.

Granaries were carefully watched and registered by $\sigma \mathbf{\imath} \tau \dot{\delta} \lambda$ o $\gamma 10$, grain accountants, the main duties of the sitologi were to receive the required amount of grain as tax or rent and store it in the $\theta \eta \sigma \alpha \hat{v} \rho \circ \mathrm{r}$, public granaeies. The sitologi measured the amount received by the $\mu \varepsilon \tau \pi \omega \delta \eta \mu \circ \sigma \imath \omega \xi \varepsilon \sigma \tau \omega$, smoothed measure.

The sitologi were considered as directors of the granaries situated in the villages, the divisions of the Arsinite nome, the toparchies and the metrpoleis. Sometimes two villages were prouped together to share one granary.

The sitologi sent returns of the amount received within five days to the strtegus of the nome, or to the $\pi \rho \alpha \kappa \tau o p \varepsilon \varsigma \sigma \imath \tau \imath \kappa \omega \nu$, on account of the various taxes or rents received. Such returns were also issued every week, every fortnight, every month, every four months and every year, these reports were made in detail, $\kappa \alpha \tau^{\prime} \alpha \nu \delta \rho \alpha$ and also as summaries, $\varepsilon \nu \kappa \varepsilon \phi \alpha ́ \lambda \iota \omega$.

The sitologi were acting either singly or jointly with associates,

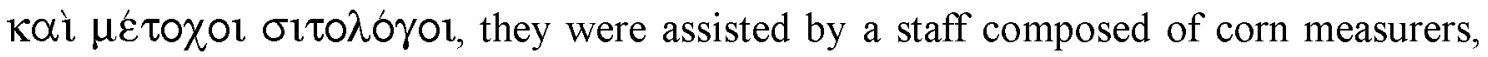
$\sigma \tau о \mu \varepsilon \tau \rho \eta \alpha \imath$ sealeres, $\sigma \phi \rho \alpha \gamma^{\prime} \sigma \tau \alpha 1$ guards, $\phi v \lambda \alpha \lambda \kappa \kappa \varepsilon$, assistants and helpers

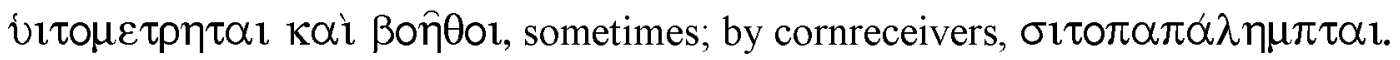

Besides; they were, principally, assisted by collectors of corn, $\pi \rho \alpha \kappa \tau o ́ p \varepsilon \varsigma \sigma \imath \tau^{\prime} \imath \omega \nu$ especially in the collection of arrears and fines or penalties, $\kappa \alpha \tau \alpha \kappa \rho i \mu \alpha \tau \alpha, \tau \grave{\alpha}$. 


\section{Text}

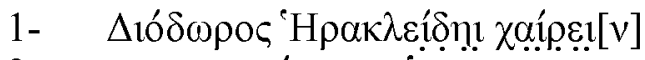

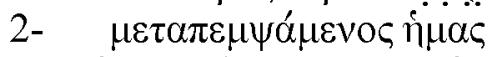

3- 'A

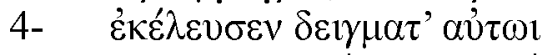

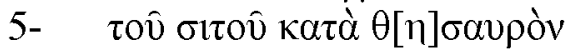

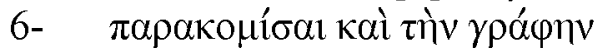

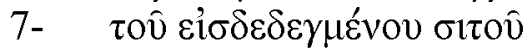

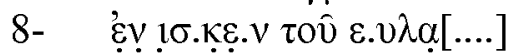

9- $\quad[\ldots . . . . . . ..] \varepsilon u ̛$ $\tau \rho . \psi \cdot \varepsilon 1$

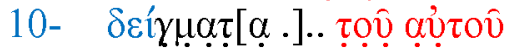

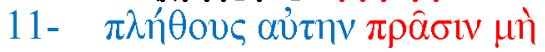

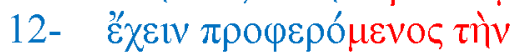

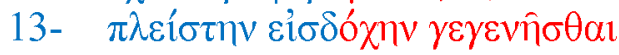

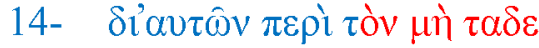

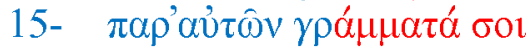

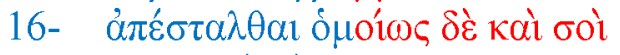

17- $\tau \hat{\omega} v \kappa \alpha \tau \dot{\alpha} \tau \dot{\alpha}[\lambda \alpha] \mu\{\beta\} \alpha v \varepsilon \tau[\ldots . .$.

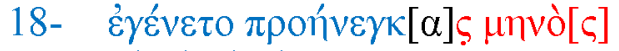

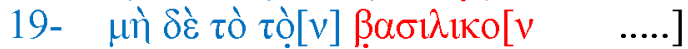

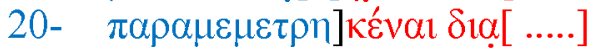

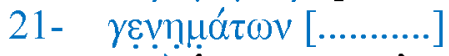

22- $\pi \varepsilon p i \dot{\varepsilon} \xi \alpha[.]. v \omega v \alpha u ̛ ⿱ 乛 ⿻[\hat{\omega} v[. .]$.

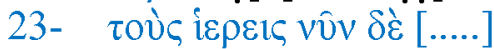

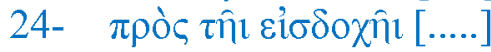

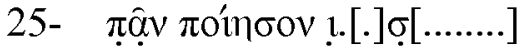

$26-\quad[\ldots \ldots . . \ldots . . . . ..] . .[\ldots \ldots .$.

\section{Translation}

Diodors to Heraclides greetings, Artemidoros sent for us to day at 15 o clock and ordered to delival for him a sample of wheat to the granery, and the document (receipt) of admitted (and when the sample the wheat have been taken into the record-office

\section{Commentary}

Line 1: As it is widely attested in the Ptolemaic era, the scribe has written an iota

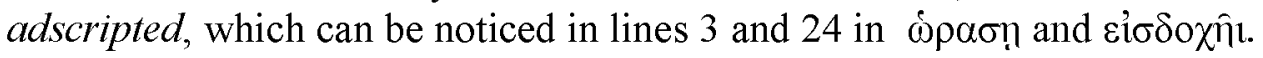

Line 3: Line 3: it would correspond generally to out 9 o' clock ,cf P.Tebt.15,2(II B.C) $\pi \varepsilon \rho \imath \omega \rho \alpha \nu$ $1 \alpha$ :about 5 o' clock ,P.Hib ,60.4 (III B.C ) $\pi \rho \circ \varepsilon \kappa \tau \eta \varsigma \omega \rho \alpha \varsigma$ before 12 o' clock.

There is no "at least a clear" paragraphus sign over the number $1 \varepsilon$ in this line.

Line 5: it is very obvious that the scribe had contracted the letters before the end of line 5

Line 11: depending upon this line as well as lines 12,14 , the average of the letters can be estimated by ca. twenty letters.

Line 13: the scribe has edited this line to the very end of the right margin (i.e there is no margin) 


\section{Business Letter}

line 15: The scribe has deleted the final alpha at the end of the preposition $\pi \alpha \rho \alpha$ before the personal pronoun $\dot{\alpha} v \tau \hat{\omega} v$ which reflects a grammatical skill.

Line 17: The scribe has forgotten to write the letter beta (See, Francis Thomas Gignac A Grammar of the Greek Papyri of the Roman and Byzantine Periods, Milano, V. I, p. 107)

Line 22: Since the epsilon, ksi and alpha are legible, as well as the suffix $-v \omega v$; the only possibility for the word by using the database of papyri.inf is $\dot{\varepsilon} \xi \alpha[\mu \underline{1}$. $] v \omega v$ 


\section{Business Letter}
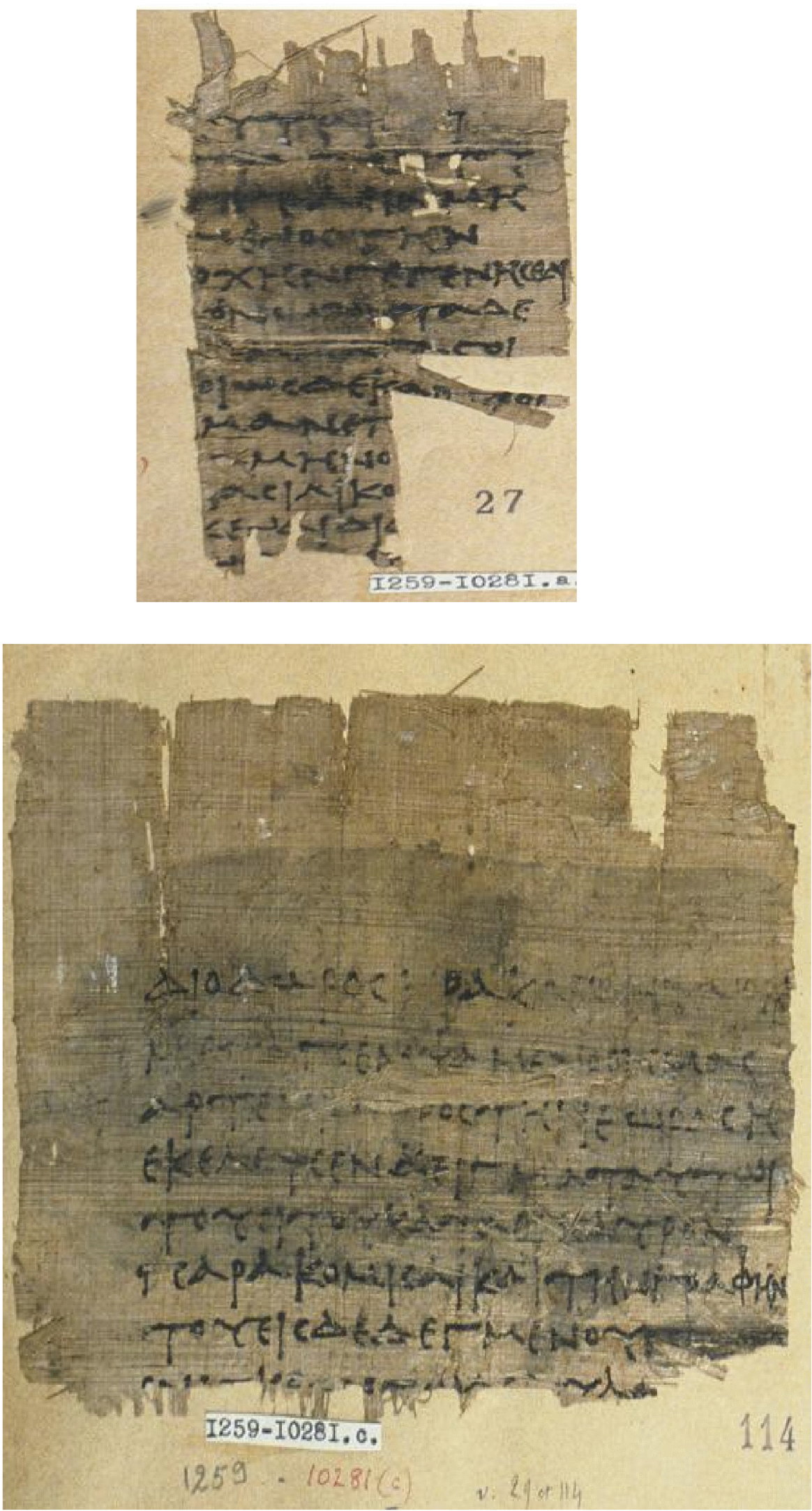


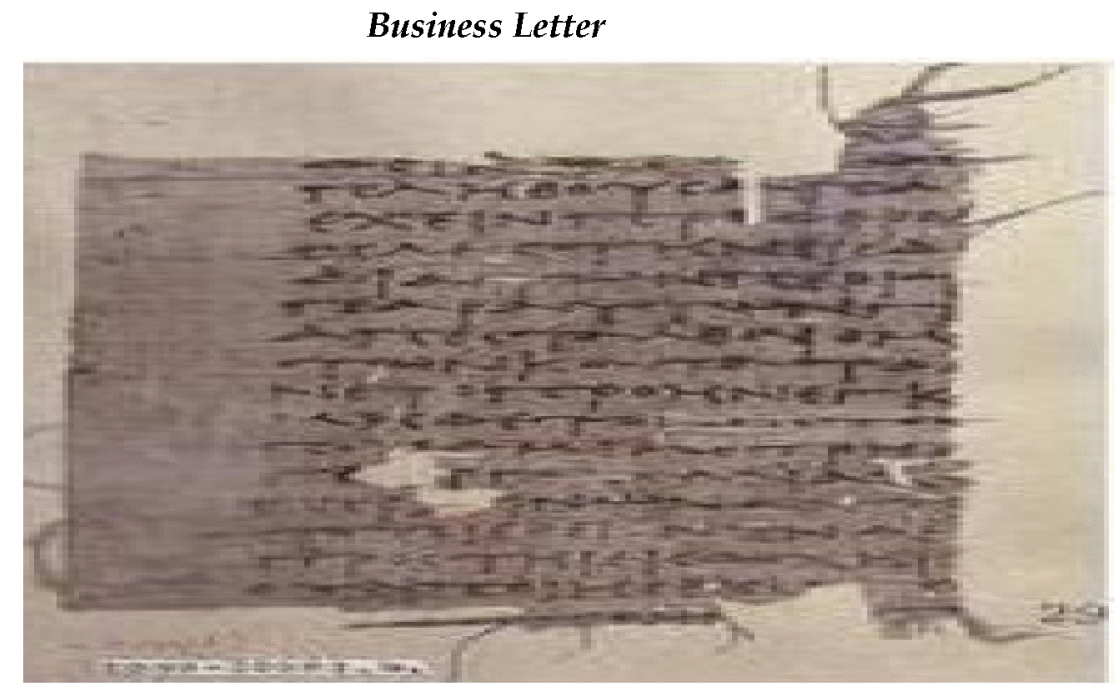

CG 12281

$a, b$ and $c$ after Photoshop

rearrangement

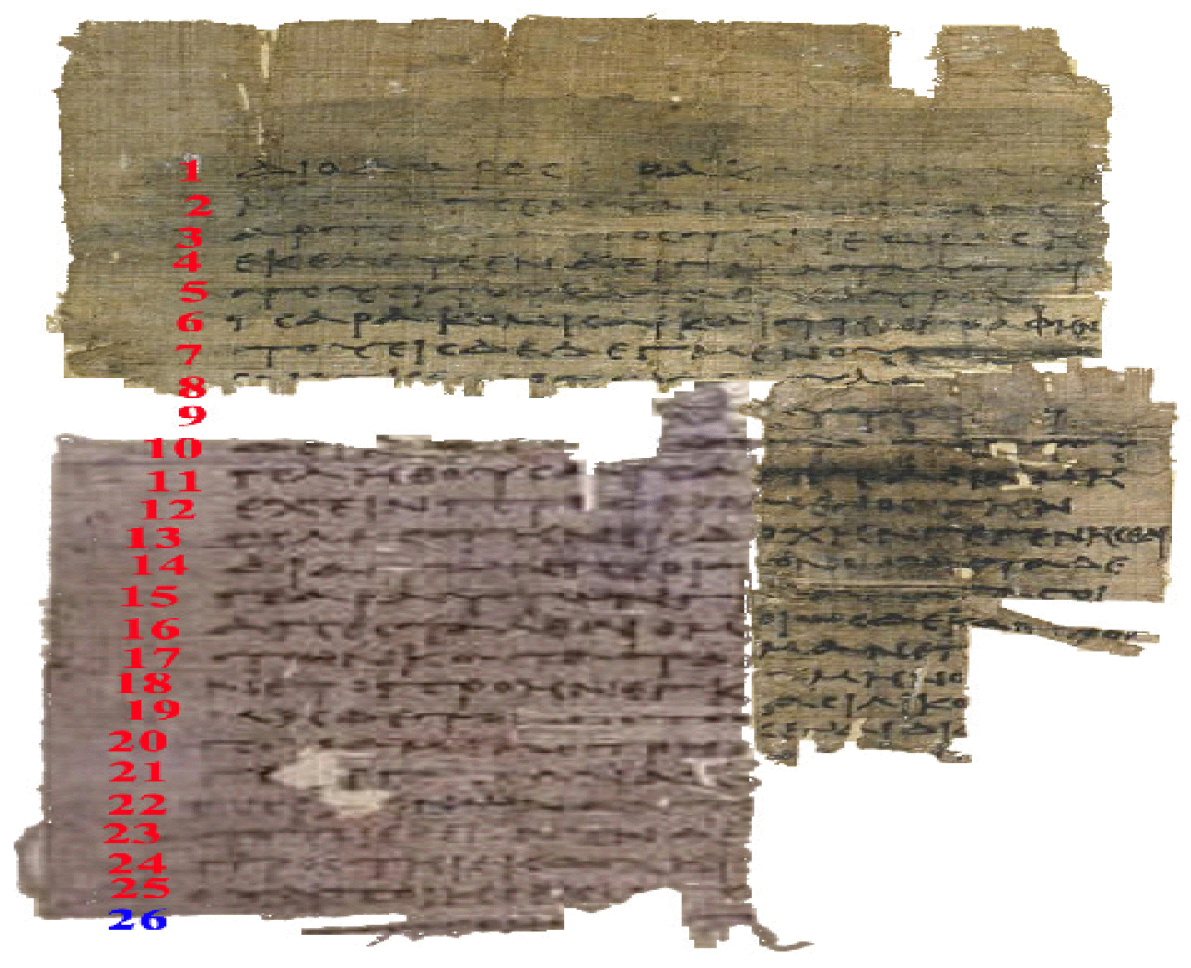

Business Letter

3rd Cemt. BCIE 